\title{
Initiating Antidepressant Medication: What is the Most Important Factor?
}

Siegfried Kasper

Received: September 15, 2021 / Accepted: December 17, 2021

(C) The Author(s) 2022, corrected publication 2022

\begin{abstract}
Treatment initiation is arguably the most important step in the management of depression. It is important at this stage of treatment to establish a therapeutic partnership between physician and patient, to facilitate shared decision-making. With specific regard to pharmacotherapy, negative attitudes and beliefs about antidepressant medications are common among the general public, and these can impact on how physicians who prescribe antidepressant medication are viewed. Some of these beliefs are that antidepressants are addictive, and that they change an individual's personality. Before initiating treatment, it is important for physicians to understand the patient's attitudes towards treatment, as well as their goals for treatment, especially since the patient's goals may not be the same as the physician's. Physicians can also identify patients who may be at risk of treatment resistance-those with more severe symptoms, at risk of suicide, with higher number of lifetime depressive episodes and comorbid anxiety disorder-and to differentiate treatment resistance from overlapping
\end{abstract}

S. Kasper $(\square)$

Center for Brain Research, Emeritus Chair of the Department of Psychiatry and Psychotherapy,

Medical University of Vienna, Spitalgasse 4, A-1090

Vienna, Austria

e-mail: siegfried.kasper@meduniwien.ac.at comorbidities. Patients need to understand that depression results from an interaction between biological and environmental factors; the use of analogies with other diseases, such as hypertension and/or a broken leg, can help in this regard. Finally, patients can be reassured that antidepressant medication is effective, and the range of agents currently available today target multiple pathways. While monotherapy is the goal, some patients will require additional treatments to manage comorbid psychiatric conditions (e.g. anxiety) or to achieve complete remission of depression. Only through complete remission of symptoms do patients achieve a level of psychosocial functioning that is equivalent to the non-depressed population. By explaining these factors to the patient, and listening to the patient's beliefs, fears and goals, physicians can forge an effective therapeutic partnership for shared decision-making and maximise the chances of success from the time of treatment initiation.

Keywords: Depression; Treatment resistance; Patient preferences; Patient education; Patient-physician partnership; Shared decision-making 


\section{Key Summary Points}

Treatment initiation is a very important step in the management of depression, and the time to establish shared decisionmaking.

Many individuals have negative beliefs about antidepressant medication, so physicians need to understand a patient's attitudes and fears before initiating treatment.

Physicians should explain the biological basis of depression, potentially using analogies of other medical conditions, and reassure patients that current drug treatments are effective.

The aim is to forge an effective therapeutic partnership for shared decision-making.

\section{INTRODUCTION}

Many factors affect the initiation of treatment in patients with depression, including public attitudes about psychiatric illness, patients' expectations of their illness and the effect of treatment, the physician's ability to accurately diagnose and manage depression, and what the physician needs to convey to the patient. The goal is to develop a therapeutic partnership between physician and patient, in which shared decisions are made about treatment in an environment of open information sharing and discussion. The aim of the current article is to review these factors in more detail and to describe how such a therapeutic relationship can be forged to maximise treatment initiation (and therefore favourable outcomes) in patients with depression. Although several evidencebased modalities are available for the treatment of depression, the focus of the present article is on antidepressant pharmacotherapy.

\section{THE PUBLIC'S BELIEFS ABOUT ANTIDEPRESSANTS}

A survey of randomly selected individuals in two German cities in 2001 showed a high rate of negative beliefs about antidepressant medication: $80 \%$ of respondents believed that antidepressants were addictive, $71 \%$ believed that antidepressants had negative effects, 69\% believed that antidepressant medication changed a person's personality, and 57\% believed that a person does not remain themselves if they take medication for depression [1]. Although these data were collected 20 years ago, many of the same attitudes persist among patients today [2].

These beliefs about antidepressant medication can affect how patients view their physicians, depending on the treatment approach they take [2]. Patients may have a poor opinion of physicians who prescribe antidepressants and may consider them to lack empathy, whereas they view physicians who prescribe only talk therapy as better and more empathetic professionals [1].

As physicians, we need to remember that many individuals hold such attitudes about antidepressant medication, and tailor our discussions with patients accordingly. The goal is to develop a therapeutic partnership with patients so that they fully participate in the process of shared decision-making and engage in self-management.

\section{PATIENTS' EXPECTATIONS}

Patients may have different treatment goals for depression. For instance, a survey conducted among American patients with major depressive disorder showed that the most common treatment goal was 'to feel better' (cited by $89.5 \%$ of patients) [3]. However, 'feeling better' may have a number of meanings, related to physical, mental, social and occupational wellbeing, particularly for patients with comorbidities, such as back pain or headache. In the US 

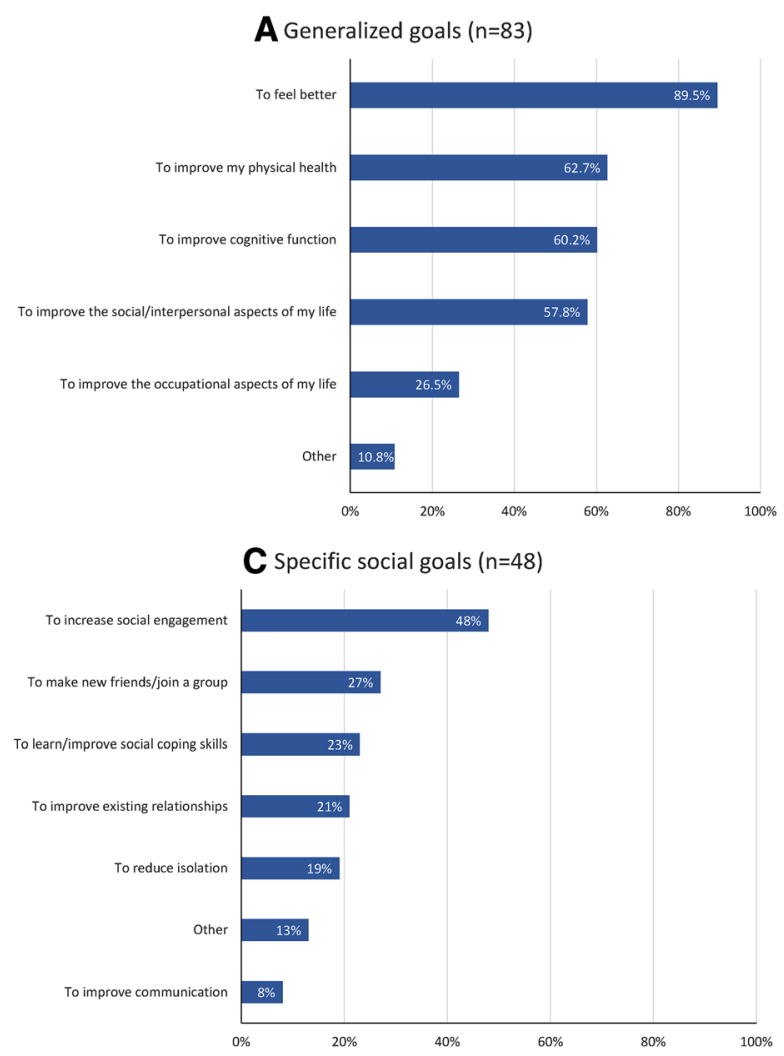

Fig. 1 Goals of US patients with major depressive disorder according to an online survey: $\mathbf{A}$ general goals, and specific goals related to $\mathbf{B}$ physical health, $\mathbf{C}$ social function, and

survey, $62.7 \%$ of patients wanted to improve their physical health, $60.2 \%$ wanted better cognitive function, $57.8 \%$ wanted to improve the social or interpersonal aspects of their lives and $26.5 \%$ wanted occupational improvements (Fig. 1) [3].

In an earlier US survey, Zimmerman and colleagues asked patients with depression to rank the importance of different definitions of remission $[4,5]$. The factor judged to be the most important was the presence of positive mental health (e.g. optimism, vigour, and selfconfidence), with $77.3 \%$ of patients rating this as very important [5]. Other factors rated as very important by more than $65 \%$ of patients were feeling like your usual, normal self $(75.6 \%)$, returning to the usual level of functioning at work/home/school (74.3\%), feeling in emotional control (71.9\%), participating in and
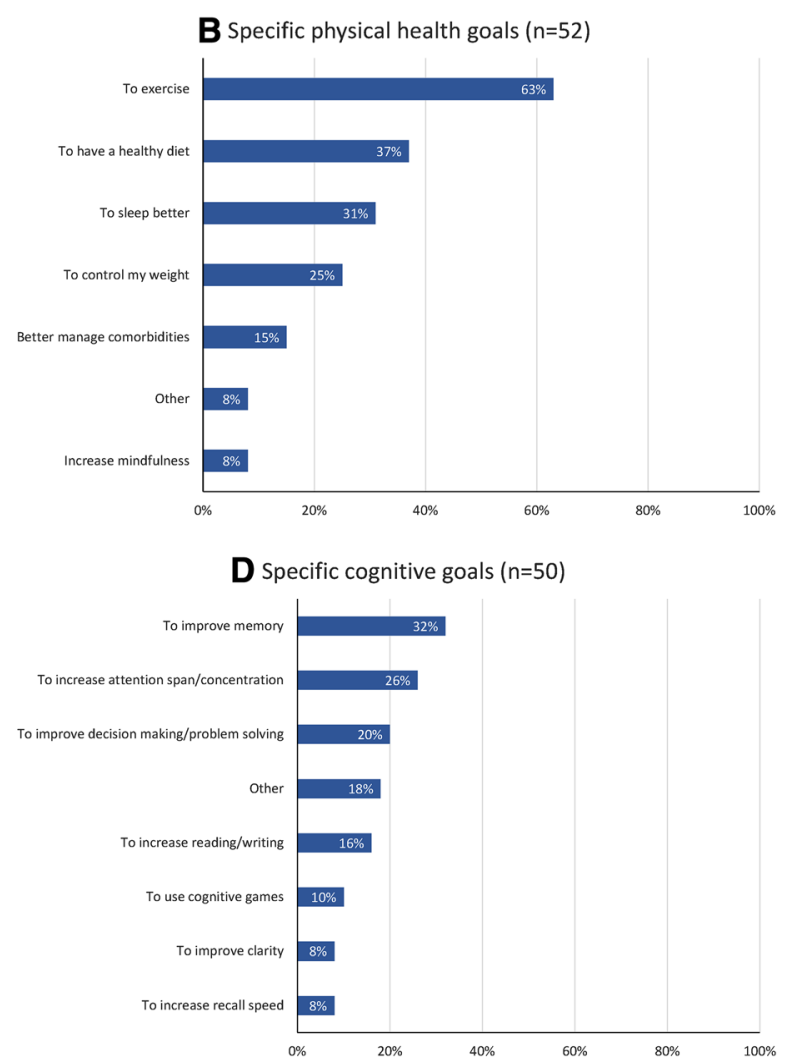

D cognitive function [3]. Patient Preference and Adberence 2019:13 959-967. Originally published by and used with permission from Dove Medical Press Ltd.

enjoying relationships with family and friends $(70.7 \%)$, absence of symptoms of depression (70.6\%), functioning well (70.3\%), a general sense of well-being (69.7\%), being able to cope with the normal stress of life $(67.9 \%)$, participating in and enjoying usual activities (67.7\%), ability to fulfil usual responsibilities $(67.2 \%)$, and having a positive outlook on life (65.5\%). However, the relative importance of various factors differed between genders and age groups [4], which highlights the need for physicians to discuss treatment goals with patients and to set individualised treatment goals and expectations based on what is important to patients.

It is also important to advise patients that their psychosocial functioning is likely to be impaired until they achieve complete remission of their depression (i.e. no diagnostic criteria present) [6]. 


\section{PHYSICIANS' EXPECTATIONS}

Physicians are concerned about the long-term course of depression, specifically about the prevention of deterioration and recurrence [7]. Effective treatment of depression early in the course of the illness increases the likelihood of response, and reduces the risk of developing treatment-resistant depression (generally defined as two or more previous treatment failures in the absence of alternative explanations, such as inadequate duration or poor adherence [8]). In addition, response rates are inversely related to the number of major depressive episodes a patient has experienced (Fig. 2), according to unpublished data from the European Group for the Study of Resistant Depression (GSRD).

The European GSRD investigated risk factors for non-response to antidepressant therapy and identified four factors associated with treatment resistance that can be easily identified during a routine clinical encounter, including the cumulative number of depressive episodes (Table 1) [9]. Interestingly, the GSRD also found that patients whose jobs were ranked high on a
Table 1 Risk factors for treatment-resistant depression $(9,11)$

\begin{tabular}{ll}
\hline Prominent risk factors & Additional risk factors \\
\hline Symptom severity & Psychotic symptoms \\
Suicidal risk & Higher number of previous \\
Higher number of lifetime & antidepressants \\
depressive episodes & Longer duration of the \\
Comorbid anxiety & current depressive episode \\
disorders & Inpatient status \\
\hline
\end{tabular}

scale of occupational levels were less likely to achieve a response to antidepressant therapy compared with individuals in jobs at the middle or low end of the scale [10]. The reasons are not clear, but the authors speculate that workplace stress could negatively affect treatment response.

It is important to identify true 'irreversible' treatment resistance, sometimes also termed refractory to treatment, i.e. depression in which the neural pathways are so damaged that antidepressant treatment is unable to restore

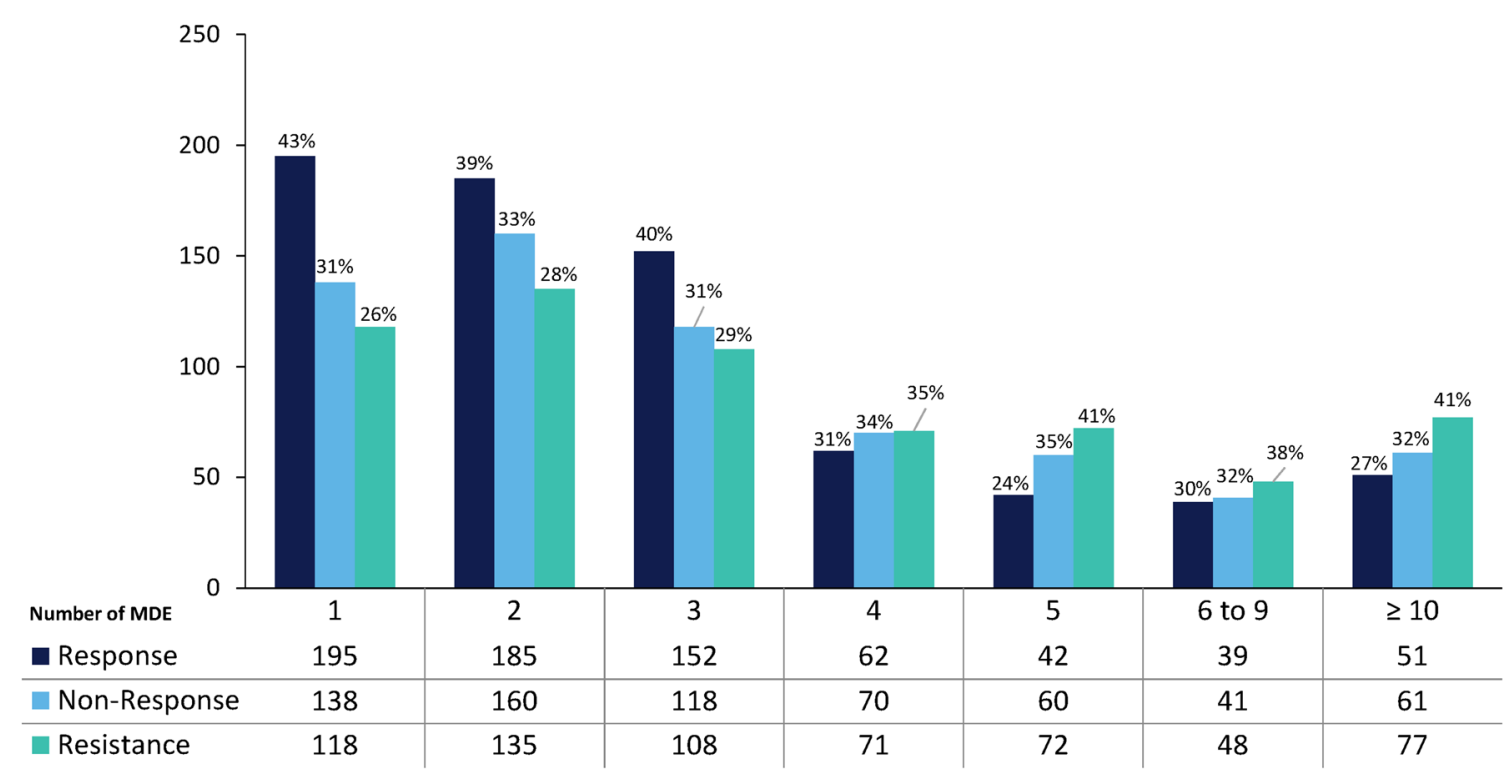

Fig. 2 Response rates to antidepressant medication according to the number of previous major depressive episodes that patients have experienced in a European database analysis $(n=2765)$ (unpublished data from the European Group for the Study of Treatment Resistant Depression, GSRD). MDE major depressive episode 
normal function [11]. The complexity of determining whether treatment resistance is truly irreversible is beyond the scope of the current article, but an important first step is to identify and exclude any overlapping, comorbid or conflating diagnoses, and to ensure that treatment is adequate in dosage and duration and unaffected by pharmacokinetic/pharmacodynamic interactions or poor adherence [11].

\section{EXPLAINING DEPRESSION TO PATIENTS}

Sometimes, it is useful for patients to have an analogy to explain illness. Commonly, the explanation is that a normal physiological response has become dysfunctional. Patients can understand that depression, like other chronic conditions such as hypertension, arise as a result of the interaction between their biological predisposition and their environment [12]. While there are limitations of using other conditions as analogies for depression, it can be helpful for patients to understand that a depressed brain takes time to heal in the same way as a broken leg does, so they have realistic expectations about the timing of their recovery and the necessity of long-term treatment, like in hypertension. It is also helpful for patients and their relatives to understand that depression has systemic effects, and that effective treatment of depression can help to resolve underlying physical conditions.

\section{MEDICATION EFFICACY}

Antidepressant medication has substantially improved in the past 60 years from the early broad-spectrum tricyclic antidepressants, to the selective serotonin reuptake inhibitors, to the present range of agents that target multiple sites of action (e.g. agomelatine).

While some patients and physicians perceive antidepressants to have limited efficacy, an analysis of meta-analyses found that the magnitude of the treatment effect of psychiatric drugs is similar to that of treatments for somatic diseases [13]. This analysis compared the effect

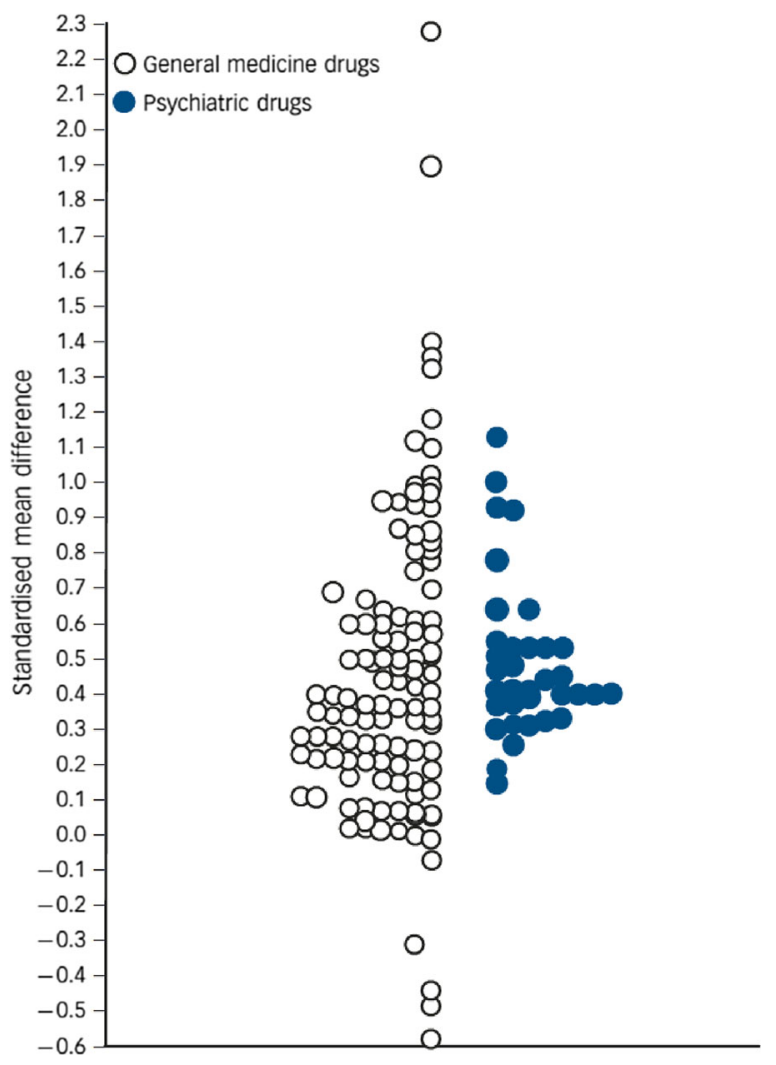

Fig. 3 Summary of the effect sizes of treatment versus placebo comparisons for psychiatric medications and those used to treat general medical conditions [13]. The median effect size of general medicine drugs was 0.37 [mean 0.45 ; $95 \%$ confidence interval (CI) $0.37-0.53$ ], compared with 0.41 (mean 0.49 ; 95\% CI $0.41-0.57$ ) for psychiatric drugs. Leucht $F$ et al. Putting the efficacy of psychiatric and general medicine medication into perspective: review of meta-analyses. Br J Psychiatry (2012) 200, 97-106. Reproduced with permission

size of the response to psychiatric drugs versus placebo in 33 meta-analyses with the response versus placebo from 94 studies in a range of medications such as antibiotics, and treatments for many somatic conditions, including hypertension, stroke, diabetes, hypercholesterolaemia, chronic obstructive pulmonary disease, chronic heart failure, hepatitis $\mathrm{C}$, and reflux oesophagitis (Fig. 3) [13, 14].

At the time of initiating antidepressant pharmacotherapy, it is important to choose the right type of medication. Monotherapy is the ideal approach, with a few drugs-agomelatine, escitalopram and vortioxetine-being both 
more effective and more acceptable than others [15]. There is also evidence showing that some drugs can act on different clusters of symptoms. For example, in a meta-analysis of six randomised controlled trials of agomelatine versus placebo, selective serotonin reuptake inhibitors or serotonin norepinephrine reuptake inhibitors, agomelatine was found to have a significantly greater effect on the severity of anxiety symptoms in the early weeks of treatment (weeks 2-4) [16]. In depressed patients with more severe anxiety, agomelatine had a significantly greater effect on anxiety and depressive symptoms than comparator antidepressants [16]. Nevertheless, patients with depression often benefit from additional medications, and polypharmacy is common. In Europe, approximately one-third of patients receiving antidepressants also take concomitant benzodiazepines or related drugs, $29 \%$ take a second anti-depressant, and $24 \%$ take antipsychotics [17]. Patients need to understand that additional medication may be required if they have comorbid conditions, such as anxiety, or if monotherapy is not sufficient to achieve complete remission of the depression.

\section{CONCLUSION}

Treatment initiation is arguably the most important step in the management of depression. Physicians need to educate patients about the biological and psychosocial processes involved in depression, so that both can collaborate in shared decision-making. This requires a clear understanding of the patient's treatment goals, as well as their needs, fears and expectations. Treatment adherence, and therefore treatment efficacy, will be maximised in the context of a therapeutic partnership between physicians and patients based on shared decision-making.

\section{ACKNOWLEDGEMENTS}

Funding. This article is based on a presentation given by Prof. Kasper at a satellite symposium entitled Road to Recovery for Depressed Patients: From Treatment Initiation to Continuity. The symposium formed part of the programme of the WPA World Congress of Psychiatry, held 10-13 March 2021. The satellite symposium was sponsored by Servier, which also provided funding for medical writing assistance. The supplement, Rapid Service and Open Access Fees were also sponsored by Servier. Open access funding provided by Medical University of Vienna

Medical Writing. The author would like to thank Catherine Rees of Springer Healthcare Communications, who wrote the first draft of the manuscript based on the presentation at WPA World Congress of Psychiatry 2021. Funding for the writing was provided by Servier.

Authorship. The named author of this article meets the International Committee of Medical Journal Editors (ICMJE) criteria for authorship for this article, takes responsibility for the integrity of the work as a whole, and has given his approval for this version to be published.

Author Contributions. Prof. Kasper prepared the content of the presentation on which this article was based, and reviewed and revised all drafts of the manuscript.

Prior Presentation. This article is based on a presentation given by the author at a satellite symposium entitled Road to Recovery for Depressed Patients: From Treatment Initiation to Continuity. The symposium formed part of the programme of the WPA World Congress of Psychiatry, held virtually from 10-13 March 2021. The content of the presentation and this article are based on work that has been previously published.

Disclosures. In the past 3 years Dr Kasper has received grant/research support from Lundbeck; he has served as a consultant or on advisory boards for Angelini, Biogen, Esai, Janssen, IQVIA, Lundbeck, Mylan, Recordati, Sage and Schwabe; and he has served on speakers bureaus for Abbott, Angelini, Aspen 
Farmaceutica S.A., Biogen, Janssen, Lundbeck, Recordati, Sage, Sanofi, Schwabe, Servier, Sun Pharma and Vifor.

Compliance with Ethics Guidelines. This article is based on previously conducted studies and does not contain any new studies with human participants or animals performed by any of the authors.

Open Access. This article is licensed under a Creative Commons Attribution-NonCommercial 4.0 International License, which permits any non-commercial use, sharing, adaptation, distribution and reproduction in any medium or format, as long as you give appropriate credit to the original author(s) and the source, provide a link to the Creative Commons licence, and indicate if changes were made. The images or other third party material in this article are included in the article's Creative Commons licence, unless indicated otherwise in a credit line to the material. If material is not included in the article's Creative Commons licence and your intended use is not permitted by statutory regulation or exceeds the permitted use, you will need to obtain permission directly from the copyright holder. To view a copy of this licence, visit http://creativecommons.org/licenses/by$\mathrm{nc} / 4.0 /$.

\section{REFERENCES}

1. Hegerl U, Althaus D, Stefanek J. Public attitudes towards treatment of depression: effects of an information campaign. Pharmacopsychiatry. 2003;36(6):288-91.

2. Nalçakan AD, Şahin EA, Yalcinkaya OK, Ak S. Antidepressant awareness and stigmatizing attitudes toward depression and antidepressants, a comparison between first and sixth-year medical students. Int J Soc Psychiatry. 2021: 0020764020985545 .

3. McNaughton EC, Curran C, Granskie J, Opler M, Sarkey S, Mucha L, et al. Patient attitudes toward and goals for MDD treatment: a survey study. Patient Prefer Adherence. 2019;13:959-67.

4. McGlinchey JB, Zimmerman M, Friedman M, Attiullah N, Boerescu D. The impact of gender, age and depressed state on patients' perspectives of remission. J Affect Disord. 2006;95(13):79-84.

5. Zimmerman M, McGlinchey JB, Posternak MA, Friedman M, Attiullah N, Boerescu D. How should remission from depression be defined? The depressed patient's perspective. Am J Psychiatry. 2006;163(1):148-50.

6. Miller IW, Keitner GI, Schatzberg AF, Klein DN, Thase ME, Rush AJ, et al. The treatment of chronic depression, part 3: psychosocial functioning before and after treatment with sertraline or imipramine. J Clin Psychiatry. 1998;59(11):608-19.

7. Gorwood P, Vaiva G, Corruble E, Llorca PM, Bayle FJ, Courtet P. The ability of early changes in motivation to predict later antidepressant treatment response. Neuropsychiatr Dis Treat. 2015;11: 2875-82.

8. Gaynes BN, Lux L, Gartlehner G, Asher G, FormanHoffman V, Green J, et al. Defining treatment-resistant depression. Depress Anxiety. 2020;37(2): 134-45.

9. Kautzky A, Dold M, Bartova L, Spies M, Kranz GS, Souery D, et al. Clinical factors predicting treatment resistant depression: affirmative results from the European multicenter study. Acta Psychiatr Scand. 2019;139(1):78-88.

10. Mandelli L, Serretti A, Souery D, Mendlewicz J, Kasper S, Montgomery S, et al. High occupational level is associated with poor response to treatment of depression. Eur Neuropsychopharmacol. 2016;26(8):1320-6.

11. Malhi GS, Bell E. Make news: treatment-resistant depression-an irreversible problem in need of a reversible solution? Aust N Z J Psychiatry. 2020;54(1):111-3.

12. Kranz GS, Kasper S. On the suitability of medical analogies, from hypertension to broken leg. World J Biol Psychiatry. 2019;20(3):171-2.

13. Leucht S, Hierl S, Kissling W, Dold M, Davis JM. Putting the efficacy of psychiatric and general medicine medication into perspective: review of meta-analyses. Br J Psychiatry. 2012;200(2):97-106.

14. Oluboka OJ, Katzman MA, Habert J, McIntosh D, MacQueen GM, Milev RV, et al. Functional recovery in major depressive disorder: providing early optimal treatment for the individual patient. Int $\mathrm{J}$ Neuropsychopharmacol. 2017;21(2):128-44.

15. Cipriani A, Furukawa TA, Salanti G, Chaimani A, Atkinson LZ, Ogawa Y, et al. Comparative efficacy and acceptability of 21 antidepressant drugs for the acute treatment of adults with major depressive 
disorder: a systematic review and network metaanalysis. Lancet. 2018;391(10128):1357-66.

16. Stein DJ, Picarel-Blanchot F, Kennedy SH. Efficacy of the novel antidepressant agomelatine for anxiety symptoms in major depression. Hum Psychopharmacol. 2013;28(2):151-9.
17. Dold M, Kautzky A, Bartova L, Rabl U, Souery D, Mendlewicz J, et al. Pharmacological treatment strategies in unipolar depression in European tertiary psychiatric treatment centers-a pharmacoepidemiological cross-sectional multicenter study. Eur Neuropsychopharmacol. 2016;26(12): 1960-71. 